\title{
Ensayo
}

\section{Pensamientos, recuerdos y conversaciones: un diálogo con Sergio Roncallo-Dow, pensador, filósofo y colega}

\section{María Catalina Cruz-González ${ }^{1}$ Julián Penagos-Carreño ${ }^{2}$ Juan David Cárdenas-Ruiz ${ }^{3}$}

\section{DOI: $10.5294 /$ pacla.2020.23.s.6}

Para citar este ensayo / to reference this essay / para citar este ensaio Cruz-González, M. C., Penagos-Carreño J. y Cárdenas-Ruiz, J. D. (2020). Pensamientos, recuerdos y conversaciones: un diálogo con Sergio Roncallo-Dow, pensador, filósofo y colega. Palabra Clave, 23(supl.), e23s6. https://doi.org/10.5294/pacla.2020.23.s.6

\section{Resumen}

Este ensayo busca dar una mirada académica, pero, sobre todo, personal de nuestra relación con el maestro Sergio Roncallo-Dow. El texto en sí es un recuerdo constante de las profundas enseñanzas que nos dejó y cómo, desde diferentes puntos de vista, queremos dejar en alto su memoria. Los acercamientos teóricos y los recuerdos que van a leer los van a adentrar en los escritos de Sergio y su forma de generar relaciones que buscaban un cambio en nuestra sociedad o, por lo menos, cuestionarnos esta. Pasando desde las teorías clásicas de comunicación, por la memoria y su mirada ecológica, hasta la construcción de textos pensados desde la comunicación pública, este ensayo busca dar fe de quién fue Sergio para nosotros y agradecerle por cada aprendizaje que nos hizo re-pensar nuestra sociedad, nuestro país y nuestro futuro.

\section{Palabras clave}

Comunicación de masas; memoria colectiva; comunicación política; cultura de masas; paz.

\footnotetext{
https://orcid.org/0000-0002-8493-1683. Universidad de La Sabana, Colombia. maria.cruz3@unisabana.edu.co https://orcid.org/0000-0003-3326-9295. Universidad de La Sabana, Colombia. julian.carreno@unisabana.edu.co https://orcid.org/0000-0003-4823-1572. Universidad de La Sabana, Colombia. juan.cardenas4@unisabana.edu.co
} 
¿Qué significa realizar un texto in memoriam de Sergio Roncallo-Dow? La locución latina, según el Diccionario de la lengua española (2014), significa "en memoria, en recuerdo". A su vez, la palabra recuerdo, etimológicamente viene de re (pasar de nuevo) y cordis (corazón). Por esta razón su definición se relaciona no solo con revivir los eventos del pasado, sino que también significa "volver a pasar por el corazón" (Etimologías, s. f.). Esa fue la intención de este ensayo, eso fue lo que hicimos. Recordar a Sergio con el corazón.

Las tres partes que lo componen son distintas, porque son visiones subjetivas sobre Sergio (¿qué recuerdo originado del corazón no lo es?). Cada autor quiso plasmar la relación que tuvo con él, los diálogos hechos y pospuestos, y las experiencias con las que aprendimos, con él, a interpretar la realidad. María Catalina Cruz-González lo hace desde la relación que tuvo con él como su mentor en las teorías de la comunicación, Julián Penagos-Carreño como su orientador en los temas de la memoria y Juan David Cárdenas-Ruiz como el conducto para reflexionar sobre el conflicto armado.

Temas diversos y pluralistas, pero que definen muy bien a Sergio, porque, si hay alguien que cumplió a cabalidad con el apotegma heideggeriano de ser-en-el-mundo, fue él. En su ausencia está presente. De seguro, Sergio adoraría el hecho paradójico de convertirse en la aplicación práctica de la reminiscencia platónica, lo que para él sería un enigma:

\footnotetext{
De la representación presente de una cosa ausente, lo que tiene lugar es la afirmación de una ausencia en medio de una presencia. Cuando el viejo jardín infantil que yo frecuentaba en 1982 aparece de nuevo ante mí, deformado, morfeado, resignificado, y sin embargo, lo reconozco, afirmo una presencia en medio de una ausencia, traigo el pasado al presente y allí tiene lugar un acto (reconocimiento) que no es pura operación de adecuación, y que hace que en tanto acto mnemónico, el reconocimiento no puede más que remitir a las dimisiones poiéticas de la reminiscencia. (Roncallo-Dow, 2009, p. 10)
}

En el recuerdo, en la reminiscencia, nuestro propósito es que permanezca a nuestro lado, porque esto no es un réquiem, sino la celebración de una vida, pues, como afirmarían Hetfiled \& Ulrich (1991) en Nothing Else Matters: 
So close no matter how far

Couldn't be much more from the heart

Forever trusting who we are

And nothing else matters.

\section{Revisitando los pensamientos de mi amigo, maestro y mentor ${ }^{4}$}

\section{Entre teorías, alienígenas, videoclips y EI Chavo del 8}

Sabiamente el maestro Yoda dijo una vez: "La muerte una parte natural de la vida es. Regocíjate por los que te rodean que en la Fuerza se transforman”. Conocí por primera vez a Sergio en un aula y, como buen maestro, decía las cosas como eran e intentaba que todos sus estudiantes ampliaríamos nuestra cosmovisión ante la realidad que nos tocó vivir. Su pasión por la academia era inigualable y su sentido por la vida era indescriptible.

Quienes conocieron a Sergio saben que su mundo oscilaba entre zombis, alienígenas, videoclips, tiburones, cine B; en pocas palabras, entre la cultura popular. Tenía una astucia para poder entender y comprender a los clásicos en nuestra época y por alguna extraña razón vio en mí algo del futuro de la comunicación, y de allí pasó de ser mi maestro a ser mi mentor. Sus primeras enseñanzas fueron a partir de las teorías de la comunicación de masas y, por supuesto, de su gran entendimiento y amor por uno de los más grandes pensadores del siglo XX: Marshall McLuhan.

Ante el pensamiento de McLuhan, Sergio era una sonda: un instrumento utilizado para investigar cualquier configuración desconocida o para recuperar un fondo olvidado-replegado y poder pensar sus efectos invisibles e imperceptibles (Roncallo-Dow, 2011). Recuerdo una de las últimas veces que lo vi, y volteándose hacia Edward Goyeneche-Gómez y hacia mí, nos dijo: "Yo lanzo sondas, a eso me dedico, hay que lanzar sondas". Y esa era su invitación, nos lo reiteraba con su gran entrevista, oportuna y elocuente, a Armand Mattelart, en la que su preocupación por la vigencia de los clásicos se veía desdibujada en un ambiente académico que empezaba

4 La palabra "revisitando" es un signo oculto de uno de los textos de Sergio Roncallo-Dow: Medios, antimedios, sondas y clichés. Revisitando a Marshall McLuhan, el explorador (2011). Es una forma de dialogar con Sergio a partir de sus diálogos con Marshall McLuhan. 
a darle más importancia a la práctica que a la teoría, y su entrevistado, dándole calma, le dijo:

\begin{abstract}
¿Los clásicos se quedan asilados? ¡No! Creo que ahí la realidad hoy de la reflexión sobre la comunicación está atravesada por revisiones, reinterrogaciones sobre el porqué de las preguntas que hacía Adorno, que hacía Gramsci, que hacía Althusser, que hacía Marx incluso sobre la comunicación, y me parece que es totalmente novedoso. No sé lo que va a resultar, pero me parece que es fundamental decir eso para decir que nada está congelado. (Roncallo-Dow, 2015, p. 647)
\end{abstract}

A eso se dedicaba Sergio, a preguntarse una y otra vez lo que decía McLuhan, Freud, Le Bon, Ortega y Gasset, Adorno, Horkheimer, Lasswell, Descartes, Kant, Foucault, y lo cruzaba con los ejemplos más contemporáneos habidos y por haber. Se comía el mundo investigando, analizando y, sobre todo, escribiendo. Y allí, en papel, plasmó su preocupación por las nuevas generaciones, por las mentes del presente, las cuales cada día es más difícil que entiendan la importancia de la teoría, y gracias a esa inquietud y a su intuición, surgió un libro que buscaba una exégesis de los clásicos, pero a partir de su relación con nuestra realidad mediática, y la promesa de su texto, escrito junto a grandes amigos como Enrique Uribe-Jongbloed y Edward Goyeneche-Gómez, era nada más ni nada menos que "llevar a los lectores valientemente a tiempos a los cuales ninguno (de ustedes) ha ido jamás y luego de regreso al futuro" (Roncallo-Dow et al., 2016, p. 20).

Allí, emprendí mi viaje como académica e investigadora, bajo el amparo de mi maestro Yoda y yo, siendo su pequeña Padawan. He leído el libro una y otra vez, y sigo fascinada por poder revisitar a los clásicos, por poderlos entender $y$, ahora, podérselos transmitir y explicar a los estudiantes.

Volver a los clásicos: teorías de la comunicación y cultura pop (RoncalloDow et al., 2016) se convirtió en una pieza clásica para el entendimiento de las teorías de la comunicación de masas, un texto que empieza su recorrido por los alienígenas desde La guerra de los mundos, de Orson Welles, hasta la serie The X-Files (1993-2018), de Chris Carter, revisitando los pensamientos de Harold Lasswell, Paul Felix Lazarsfeld, Charles Wright Mills, entre otros, y la teoría funcionalista, la cual hasta el sol de hoy no ha cam- 
biado radicalmente, pues seguimos ante la posibilidad de pensar la sociedad como un sistema coherente y pululante de dispositivos que tendrían como fin mantener ese orden, mantener el equilibrio (Roncallo-Dow et al., 2016, p. 23). Y qué mejor forma para entenderlo que a partir de El Chavo del 8 (1971-1980): todo empezó cuando doña Florinda y don Ramón se asociaron para vender churros, ¿recuerdan? Pues bien, estas dinámicas nos permiten entender las lógicas del capitalismo, la idea de distinción y movilidad social, y las narrativas de la crisis (y más en tiempos de covid-19). Sergio me recordó ese capítulo un domingo 11 de noviembre, y como siempre decía: "vivo para dar".

Su amor por la música quedó plasmado en el entendimiento semiótico e ideológico de Roland Barthes a partir de los videoclips en que hacía énfasis en la posibilidad de pensar los fenómenos mediáticos como lugares de configuración de los mitos (Roncallo-Dow et al., 2016, p. 59). No está de más recordar los clásicos: Paranoid (1970) y Iron Man (1970) de Black Sabbatah; Closer de Nine Inch Nails; People of the Sun de Rage Against the Machine; Take on Me de a-ha; Bohemian Rhapsody de Queen, entre otros; su fin teórico: reconfigurar la forma de ver la música, pues esta pasaba a ser visual. Lo que ocurría en nosotros era un cambio en la forma como veíamos y percibíamos el mundo: la construcción de significado desde los videoclips hacía que ampliásemos nuestros juegos del lenguaje, tal y como lo reiteraba Wittgenstein, autor que Sergio siempre tenía presente en sus escritos:

Es evidente que sin estos niveles de reconocimiento y aceptación re-
sultaría bastante difícil hablar de la iconicidad del ícono en el sentido
en el que lo sugiere McLuhan, toda vez que lo que parece desplegar
su propuesta, es, precisamente, la fractura y posterior recomposi-
ción de los juegos del lenguaje —retomando el hoy clásico término
de Wittgenstein (1999)—en virtud de una visión de mundo cambian-
te. Más sencillo aún: hay una mutación en los códigos que estabilizan
el significado. (Roncallo-Dow et al., 2016, p. 60)

Y, por supuesto, no podemos dejar a un lado el gran mito que Sergio nos dejó junto con su banda: su videoclip Bum Bum de Los Pussylánimes, una pieza que hace una yuxtaposición de imágenes tanta sonoras como visuales, en atención a la lírica del grupo Escarcha (2002): 
Ay que bueno es tener tu cariñito entero,

suavecito como un caramelo,

toditito para mí.

Y me muero cada día por tener tus besos,

que me quieras como yo te quiero,

solo vivo para ti.

Pero claro, sin dejar a un lado el espíritu rockero que tanto identificaba a Sergio.

De la misma forma, Sergio siempre revisitaba los pensamientos de Adorno, Horkheimer, Habermas, Marcuse y Benjamin, para los postulados de la teoría crítica y, por supuesto, lo hacía a partir de las nuevas dinámicas mediáticas como YouTube, plataforma que reconfiguró el aura de canales como MTV o VH1, canales moribundos que se habían sumergido en el clandestino mundo de los reality shows; Sergio nos lo recuerda: "YouTube otorga el aura de lo viral, el aura de lo autogestinado, el aura efímera de lo audiovisual-visible que no produce memoria. Un aura, si se nos permite el término, más punk" (Roncallo-Dow et al., 2016, p. 107). ¿Se imaginan la reacción de Adorno ante estas palabras?

Sergio debe estar teniendo las conversaciones más rockeras con McLuhan, Adorno, Foucault, Wittgenstein, Platón, entre otros, mientras escribo sobre él y su legado. Imagino que deben estar hablando sobre la existencia de los alienígenas (que, por cierto, sí existen), sobre las nuevas extensiones o prolongaciones que el ser humano ha creado (como The Pirate Bay) y sobre quién tendrá la razón sobre el futuro de la humanidad después del covid-19, ¿Slavoj Žižek o Byung-Chul Han?

Es cierto que la muerte es una parte natural de la vida, pero la inesperada partida de nuestro amigo, colega y maestro nos recuerda que damos por sentado la existencia del otro y que este va a estar con nosotros durante mucho tiempo, pero la vida es frágil, insospechada, a veces dura y tosca. La verdad es que siempre me regocijaré con el recuerdo de Sergio, con sus enseñanzas y su legado, y hoy él se transforma en la Fuerza, hoy él es el mensaje.

May the Force be with you. 


\section{Las conversaciones que tuvimos}

\section{La Memoria, la técnica y los recuerdos}

Sergio fue fuente de inspiración para muchos de nosotros. De no pocas conversaciones que teníamos con él surgían ideas, tesis o teorías que iluminaban los recorridos académicos de nuestros respectivos campos de estudio. Mi caso no fue la excepción. Recuerdo un diálogo en específico, cuando recién comenzaba mis estudios de doctorado en la Universidad de Valencia, España, y trataba de diagramar un marco teórico que me permitiera enlazar el tema de mi tesis (la memoria) con los medios de comunicación. Algún pensamiento predictivo tenía en cuanto a que el eje de análisis debíar basarse en algún componente técnico y, de inmediato, el nombre de Marshall McLuhan se me vino a la mente. El experto en este tema era precisamente, Sergio.

Le escribí un correo para preguntarle por la posibilidad de conectarnos de forma virtual. Pues yo estaba en Valencia y él en Bogotá. Accedió de inmediato. Con lo que demostró su gran generosidad de estar disponible para cuando se lo necesitaba. Estuvimos más de dos horas conectados, conversando, hablando, bromeando y aprendiendo, sobre todo yo de él. De esa conversación se origina una de las hipótesis de mi trabajo de doctorado: que la memoria depende del medio que la transmite y que, por tanto, adquiere las propiedades y las características de ese medio que la propaga, es decir, que el medio es la memoria. Recuerdo que le hice esa pregunta: “Entonces, profe, podría ser que ¿el medio es la memoria?”.

Él reaccionó de manera tranquila, como si fuera algo obvio o como si lo estuviera pensando mejor. Después afirmó: "Puede ser, sí, pero se debe trabajar mucho y arreglar algunos detalles".

La conversación giró, entonces, en torno a McLuhan y los conceptos de técnica y tecnología; más tarde, con libros y documentos que él mismo me compartió. Me referiré aquí a su tesis de doctorado El apotegma mediático: la noción de medio en Marshall Mcluhan (Roncallo-Dow, 2010). En esta Sergio desarrolla toda una reflexión en torno a la teoría del canadiense y desentraña el significado de la frase "el medio es el mensaje". 
Ahora, debo confesar algo, mi poco conocimiento de Marshall McLuhan había hecho que cayera en la confusión común de creer que el filósofo de Edmonton se refería como medio al aparato-medio de comunicación. Sergio me "liberó" de esa errónea suposición. En su tesis, aclara que McLuhan entiende por medio un ambiente estructura de significación estructurante y estructurado por la técnica que, a su vez, modifica el entorno que quiere entender. Por lo que se aleja de la visión instrumentalizadora de los medios de comunicación.

Para llegar a esa conclusión, hace un recorrido teórico-filosófico acompañado de Bernard Stiegler, André Leroi-Gourhan y Evandro Agazzi, Gilbert Simondon, Michel Serres, Peter Sloterdijk, Donna Haraway, entre otros, e incluso se acerca a los presupuestos teóricos de Heidegger. Afirma Roncallo-Dow (2010) que la dificultad para entender el apotegma de McLuhan se debe a un proceso histórico de separación realizada por el ser humano de la cultura y la técnica:

\begin{abstract}
La paulatina des-humanización de la idea de la técnica como algo que se opone a la cultura ha llevado a su in-comprensión como elemento fundamental para entender los modos de interacción y cambio social. De ahí la necesidad de re-pensar la opacidad con la que la tecnología ha sido abordada y su particular relación epistémica y factual con la técnica. (p. 20)
\end{abstract}

Por esta razón, se basará en estos autores y sus teorías para re-integrar la idea de que el ser humano es inherente a la técnica a fin de llevar a cabo ese proceso de corte transductivo para apropiarse del medio natural que lo rodea y alejarse de la visión de corte binaria e instrumental de la técnica.

De estos lugares "no visitados" (Roncallo-Dow, 2010, p. 12) parte su reflexión para comprender la verdadera significación de la frase "el medio es el mensaje". Será Stiegler (2002), con La técnica y el tiempo, con quien empezará este recorrido y su alejamiento "de esta perspectiva naturalista y racionalista en pos de una postura más heterodoxa pero que, a la vez, me permita pensarlas desde su ser-con el hombre” (p. 23). Además, Stiegler le da la posibilidad a Sergio de defender su posición un tanto apologética de los filósofos griegos, sobre todo de Platón: "Stiegler [...] recupera 
la idea platónica de la técnica entendida como un saber-hacer-algo" (Roncallo-Dow, 2010, p. 21).

Sergio menciona que Stiegler habla de la técnica como "lo impensado", en la perspectiva de ser un término incomprendido, en cuanto a que ha sido vista "desde una suerte de ontología objetual que la reduce a una especie de alteridad reconocida solo en tanto útil (Roncallo-Dow, 2010, p. 20).

Sergio aboga por la visión de la técnica y la tecnología como ese saber-hacer del ser humano con el que este interpreta el entorno que lo rodea y se lo apropia. Este proceso implica una producción de conocimiento. Es decir, la forma como el hombre entiende el mundo es por medio de un instrumento con el que a su vez lo resignifica.

Todo empieza como lo expresa Sergio, desde un olvido mítico. El del titán Epimeteo, aquel encargado de darle cualidades a ese ser recién creado por Zeus: el ser humano. Sergio narra el mito basándose en Stiegler (Roncallo-Dow, 2010, pp. 150-151). El mito cuenta que Epimeteo se olvida de darle al hombre la cualidades necesairas para relacionarse con el entorno, entonces, Prometeo, su hermano, suple la falencia, regalándole el fuego (la técnica) a los hombres, que ha robado de los dioses de Olimpo.

Sergio llama la atención sobre que la técnica surge a partir de un olvido y un robo (Roncallo-Dow, 2010, p. 41). Pero advierte que aquí está inmersa esa doble poiésis de la técnica y tecno-logía desde lo humano. Esto subyace a la idea de que el hombre se apropia del mundo con un invento y a su vez lo resignifica a partir de ese objeto. Es la epifilogénesis, definida por el mismo Stiegler, en un párrafo transcrito por Sergio:

Una acumulación recapitulativa, dinámica y morfogenética (filogénesis) de la experiencia individual (epı), que designa la aparición de una nueva relación entre el organismo y su medio, que también es un nuevo estado de la materia: si el individuo es una materia orgánica y por tanto organizada, su relación con el medio (con la materia en general, orgánica e inorgánica) cuando se trata de un quién, está mediatizado por esta materia organizada aunque inorgánica que es el órganon, la herramienta con su papel instructor (su papel de ins- 
trumento), el qué. Es en este sentido que el quién inventa al qué tanto como aquel es inventado por este. (Stiegler, 2002, citado por Roncallo-Dow, 2010, p. 39)

Este tipo de "mayéutica tecnológica", término utilizado por Sergio, hace evidente que la técnica es inherente al ser humano, es por ella que se apropia del mundo y lo resignifica. La escritura por medio de sílex es una forma de relacionarse con el ambiente y de resignificarlo, pues "lo humano se hace humano a partir de lo protésico" (Roncallo-Dow, 2010, p. 45). Se hace evidente que Sergio fundamenta uno de los pensamientos más importantes de la teoría de McLuhan en que los medios son las extensiones de los sentidos del hombre. El ser humano construye artefactos que son herramientas que utiliza para apropiarse, comprender y resignificar el mundo que lo rodea. Son extensiones de sus sentidos por la carencia y el olvido de Epimeteo, pero son naturales en la medida en que son inherentes a él, y son lo que lo definen como humano. En este sentido, Sergio está de acuerdo con Stiegler en que no se pueda separar la técnica de la cultura, la misma posición de McLuhan.

En este sentido, para Sergio, McLuhan $(1972,1996)$ ve los medios desde esta perspectiva de relación de doble poiésis técnica-tecnológica. Los medios son agentes técnicos que son estructura, pues tienen todo un constructor significativo interno para ser y cumplir con la función para la que fueron creados, y son estructurantes en la medida en que representan el entorno, pero también lo transforman. Desde esta perspectiva, "el medio es el mensaje", pues el sistema discursivo de la herramienta no solo se relaciona con el entorno, sino que también lo modifica, tanto física como significativamente. Utilizando un ejemplo del mismo McLuhan, en la época de la industrialización, la locomotora de vapor modificó el espacio y transformó los paisajes por donde se tenían que construir los rieles. Las ciudades y los pueblos tuvieron que dar lugar a las estaciones. Por otro lado, también se modificaron las concepciones de tiempo, pues los recorridos se hicieron más cortos, por lo que cambiaron las dinámicas sociales y de trabajo. A su vez, la concepción de las distancias se modifica pues en ese momento son ahora más cortas. También los procesos que conllevan la utilización del tren supusieron la introducción de nuevos códigos de conducta y de comportamiento que conllevaron transformaciones culturales. 
Entonces ¿el medio es la memoria? La respuesta requirió un largo discurrir teórico que no es posible de explicar, dado que este no es el espacio ni el momento. Solo debo decir que en esas interminables noches de insomnio en las que la desesperación, la ansiedad y la desorientación se hicieron presentes el pensamiento de Sergio (e incluso Sergio mismo) siempre estuvieron ahí para orientarme hacia la dirección correcta. Si se me permite la metáfora, Sergio fue como ese faro que indicaba el camino de la certeza hacia esa orilla sabia, cuando estaba inmerso en el pavoroso mar de la duda.

\section{La política y la realidad nacional}

\section{Esbozos de algunas conversaciones, proyectos e ideas}

Desde que conocí a Sergio vi en él a una persona que cada vez era más apática, más cínica, frente a los políticos, no tanto así frente a la política. Así pareciera estar en otro plano, nunca se rehusó a mantener el contacto con los asuntos públicos. Aunque poco hablaba de ello, y seguramente poco se encontrará en su obra referencias explícitas a cuestiones "político-partidistas" y problemas de la coyuntura nacional, era un académico muy sensible a la realidad política y tenía posturas muy claras frente a todo lo que ocurría en la política nacional.

Quizá, siendo un poco atrevido, creería que su acercamiento a estos problemas en sus últimos trabajos se dio en una dirección desde las metodologías hacia los problemas de la agenda. Desde hace unos años, y junto con la profesora María Catalina Cruz-González, abrimos un semillero de análisis del discurso en el que fueron surgiendo distintos estudios que lograron generar un vínculo entre la comunicación política y los aportes investigativos de Sergio.

Estudios de discurso, análisis de contenido, comprensión de marcos de interpretación, entre otros métodos, fueron utilizados para abordar problemas estructurales y coyunturales con un grupo de estudiantes que se fue interesando en la investigación en comunicación política y opinión pública, desde una perspectiva que fue dejando ver unos primeros rasgos "positivistas”, como él mismo lo diría. Allí, creo, empezaba una nueva faceta 
investigativa a surgir, no en detrimento de sus otros intereses, al contrario, sus aportes permitían darles mayor rigor y profundidad a muchas preguntas y procesos de investigación en los que afortunadamente pudimos contar con su presencia y sapiencia.

Una mañana hace ya casi tres años, septiembre de 2017, recibí una llamada de Sergio contándome que tenía una idea y que quería que lo acompañara. Un año antes, los colombianos en una apretada votación habían decidido no refrendar los acuerdos de paz del Gobierno con las Fuerzas Armadas Revolucionarias de Colombia (FARC), lo que, a muchos, incluidos nosotros, nos había sumido es una especie de desamor político, aunque estábamos acostumbrados a estar siempre del lado perdedor de las elecciones en el país.

Junto con el profesor Juan Carlos Gómez Giraldo, empezamos los tres a trabajar en la confección de una convocatoria a un libro que abordara el papel de la comunicación dentro del posconflicto, pero, sobre todo, que reivindicara el rol de la academia en un país que para la fecha estaba sumido en la total incertidumbre ante la derrota del plebiscito, la continuidad de la implementación de los acuerdos, llena de obstáculos y problemas, y lo que se empezaba a avizorar como la llegada del Gobierno Duque que estaba en contra de los esfuerzos, que no solo desde el Gobierno Santos, sino desde distintos sectores sociales se habían dado para alcanzar la paz y que el 2 de octubre de 2016 habían sido derrotados.

Movidos por la decepción que nos generaba lo que estaba pasando frente a la ilusión de ver al país en paz, que parecía estar sucumbiendo, y conscientes de que como académicos teníamos que sentar una voz y darles voz a muchas otras personas que venían investigando, pensando y produciendo conocimiento en torno a la pazy la comunicación como herramientas de construcción de paz dentro del posconflicto.

Con esa idea en la cabeza, hicimos pública la convocatoria y empezamos a recibir textos que, a la postre, muchos de ellos terminaron siendo parte del libro Nosotros Colombia: comunicación, paz y posconflicto. 
Para conocer el pensamiento de Sergio frente al fenómeno que tratábamos de abordar en la publicación, basta con leer detenidamente el prólogo del libro. Allí, él rescataría la idea del reconocimiento del otro, no solo desde la tolerancia, sino también desde la legitimidad de las capacidades de los demás como requisito ineludible para alcanzar la paz. Al respecto, Roncallo-Dow et al. (2019):

Colombia no ha vivido momentos sencillos en medio de la búsqueda de la paz. Los continuos atentados terroristas, las rupturas comunicativas y, más recientemente, los debates con poco argumento que se dan en las redes sociales han dificultado decisivamente las dinámicas de cambio. La polarización política que se ha vivido en los últimos años ha roto las promesas de reconocimiento del otro. (p. 12)

Este libro no solo buscaba reivindicar la relación entre la academia y los procesos de construcción social, además, era un intento por reconstruir y evidenciar la relación fundamental entre la comunicación, la convivencia pacífica y la deliberación pública. En ese orden de ideas, "debería pensarse la paz y el posconflicto como el resultado de una construcción colectiva en la que los juicios conforman la intrincada red de nuestro lenguaje político. Pero el lenguaje, como una ciudad, está en continua transformación y evoluciona. Así debe ser comprendida la política” (Roncallo-Dow et al., 2019, p. 13).

En tres partes y doce capítulos, quedarían consignados los aportes de un grupo diverso de académicos que, desde perspectivas divergentes, abordaron el fenómeno de la comunicación y la paz. Siguiendo el espíritu de la aproximación al problema, se abrieron las puertas a aportes locales, regionales y nacionales, abordajes desde la música, la cultura, la tecnología, el arte, la literatura, la historia y los estudios de medios de comunicación, en una obra que terminaría siendo un gran aporte al entendimiento de camino tortuoso de la implementación de los acuerdos de paz y, a la vez, una bocanada de oxígeno y "seguridad ontológica", en un momento en el que el país atravesaba un momento muy difícil y se requerían aportes para parar, pensar, reflexionar y mostrar que era posible seguir teniendo esperanzas, siempre y cuando volviéramos a pensarnos como un nosotros. 
Si bien esta publicación no representó un aporte sustancial desde lo teórico, como la mayoría de los libros, artículos, charlas y reflexiones de Sergio, puedo dar fe de que fue uno de los proyectos que más movió su alma, como lleva por título la introducción del libro.

Siguiendo ese camino, y dentro del trabajo en el semillero de investigación, surgió la inquietud por analizar los discursos de los actores políticos involucrados en el proceso de implementación del proceso de paz, buscando a través del lenguaje trazos de los horizontes de país que se construían en esas enunciaciones. Así, nació un nuevo proyecto que buscaba analizar críticamente el discurso de Rodrigo Londoño, “Timochenko”, el día en que las FARC hicieron públicamente su tránsito hacia la política partidista formal, el 1 de septiembre de 2017, frente a una Plaza de Bolívar atiborrada de personas. Este ejercicio, como se planteó en el artículo, estaba motivado por "la idea de la lucha presente en el acto comunicativo y que un análisis del lenguaje como una forma de práctica social nos permite estudiar los modos en que la dominación se (re)produce y se resiste con los discursos" (Roncallo-Dow et al., 2020, p. 1774). De ahí se desprende un análisis que buscaba establecer en tres dimensiones las orientaciones discursivas de líder de las FARC, en especial desde la perspectiva de lo "no dicho", y que apuntalaban posturas relativas a la visión sobre el país, las FARC como partido político y su visión frente al futuro del país. Todo esto quedaría plasmado en el artículo "Un análisis del discurso de Rodrigo Londoño Echeverri, Timochenko, el 1 de septiembre de 2017 en la Plaza de Bolívar”, publicado en la revista Izquierdas.

El último proyecto que logré trabajar con Sergio fue una investigación sobre el problema del asesinato de líderes sociales y su impacto en las estrategias de comunicación en redes sociales por parte de los parlamentarios colombianos. De la mano del semillero de investigación, buscamos identificar el tratamiento que hacían los parlamentarios colombianos en sus cuentas de Twitter, a partir de reconocer su naturaleza de representantes de la ciudadanía y su carácter de representación regional y local, en que más se presentan estos actos violentos. 
Este estudio supondría el tránsito de Sergio hacia un primer ejercicio investigativo mayoritariamente cuantitativo abordado con el mismo rigor y la misma disposición de siempre. Los resultados de este proyecto se presentaron en distintos eventos académicos nacionales e internacionales, y actualmente está en proceso de publicación un artículo en la revista Análisis Político de la Universidad Nacional de Colombia titulado "Los líderes sociales en la agenda digital de los congresistas colombianos: entre la corrección política y la denuncia directa”.

Esto es, en líneas generales, un poco del trabajo que venía emergiendo en este campo y que seguramente iba a seguir creciendo. Ya estábamos pensando en investigar sobre las conmemoraciones de la Masacre de El Salado, la construcción de la imagen política en Instagram y la deliberación en redes sociales sobre el fenómeno de los migrantes venezolanos.

Seguramente nuestras conversaciones hubieran seguido, más aún en medio de un mundo cada vez más convulsionado, carente de sentido y en permanente búsqueda de certezas.

\section{Conclusiones}

El aporte de Sergio como pensador, académico y filósofo es algo inconmensurable. Estamos seguros de que dejó una huella en todos aquellos amigos, estudiantes y colegas que tuvieron la fortuna de cruzarse en su camino.

Más allá de su extensa bibliografía y el sinnúmero de aportes para poder, a la vez, entender y cuestionar el mundo que nos rodea, su mayor enseñanza versa sobre cómo pensar el mundo, cómo atreverse a romper los moldes de lo establecido, plantearse preguntas distintas de los que la mayoría se hace y experimentar aproximaciones no convencionales para problematizar lo que pareciera estar dado por sentado.

Su influencia, su vigencia y su relevancia trasciende su obra material y su presencia física. Los pensamientos, los recuerdos y las conversaciones que acá compartimos son solo una muy pequeña parte de su legado, marcado por la capacidad de abordar, al mismo tiempo con libertad y pasión, cual- 
quier problema o pregunta de investigación, la discusión sobre un partido de fútbol, sus impresiones sobre una telenovela o una serie clásica de televisión, sus posturas sobre el acontecer político nacional, sus interpretaciones sobre los fenómenos históricos y, por supuesto, la esencia del rock and roll.

En estos tiempos que vive el mundo, echamos de menos la capacidad de parar, reflexionar, pensar y dar una luz para acercarnos a la incertidumbre que nos embarga como civilización. Donde todos apuntan hacia los mismos lugares y las mismas explicaciones, seguramente Sergio estuviera dándonos una valiosa y necesaria mirada, muy a su estilo, y nos señalaría que todo iba a estar bien. Y como el gran Joey Ramone (2012) nos diría: "rock and roll is the answer".

\section{Referencias}

Escarcha. (2002). Bum bum. En Escarcha. Sony Music.

Hetfiled, J. \& Ulrich, L. (1991). Nothing Else Matters. En Metallica. Blackened Recordings.

In memoriam. (2014). En Diccionario de la lengua española. https://dle.rae. es/in\%20memoriam

McLuhan, M. (1972). La Galaxia Gutenberg. Aguilar.

McLuhan, M. (1996). Comprender los medios de comunicación: las extensiones del ser humano. Paidós.

Ramone, J. (2012). Rock and roll is the answer. En Ya Know? BMG.

Recordar. (s. f.). En Etimologías. http://etimologias.dechile.net/?recordar

Roncallo-Dow, S. (2009). Anámnesis y reconocimiento: una posible lectura de la teoría de la reminiscencia de Platón. A Parte Rei, 61. http:// serbal.pntic.mec.es/ cmunoz11/roncallo61.pdf 
Roncallo-Dow, S. (2010). El apotegma mediático: la noción de medio en Marshall Mcluhan (Tesis doctoral, Pontificia Universidad Javeriana, Bogotá, Colombia). https://repository.javeriana.edu.co/handle/10554/6727

Roncallo-Dow, S. (2011). Medios, antimedios, sonda y clichés: revisitando a Marshall McLuhan, el explorador. Signo y Pensamiento, 31(59), 122-138. https://revistas.javeriana.edu.co/index.php/signoypensamiento/article/view/2437

Roncallo-Dow, S. (2015). “Sin teoría no hay posibilidad de evoluación de las prácticas”: diálogo con Armand Mattelart. Palabra Clave, 18(3), 641-649. https://doi.org/10.5294/pacla.2015.18.3.1

Roncallo-Dow, S., Cárdenas-Ruiz, J. C. y Gómez-Giraldo, J. C. (2019). Nosotros Colombia: comunicación, paz y posconflicto. Universidad de La Sabana. https://doi.org/10.5294/978-958-12-0515-8

Roncallo-Dow, S., Cárdenas-Ruiz, J. D. y Cruz-González, M. C. (2020). Un análisis del discurso de Rodrigo Londoño Echeverri, Timochenko, el 1 de septiembre de 2017 en la Plaza de Bolívar. Izquierdas, 49. http://www.izquierdas.cl/images/pdf/2020/n49/ art90_1772_1803.pdf

Roncallo-Dow, S., Uribe-Jongbloed, E. y Goyeneche-Gómez, E. (2016). Volver a los clásicos: teorías de la comunicación y cultura pop. Universidad de La Sabana.

Stiegler, B. (2002). La técnica y el tiempo. Vol. 1: El pecado de Epimeteo. Hiru. 